\title{
Centrando el Reino, Centrando al Rey: Creación y Legitimización Maya en San Bartolo
}

William Saturno

\section{Resumen}

En el Preclásico Tardío, San Bartolo ya poseía muchas de las características que se esperaría encontrar en un centro grande del Período Clásico; una jerarquía residencial bien diferenciada y espacios ceremoniales monumentales claramente definidos, así como sus murales narrativos policromados y textos jeroglíficos pintados. Las escenas murales en San Bartolo traen a la mente tanto elementos del Códice Fejervary-Mayer como del Códice Borgia. En todos los casos, el sacrificio divino está asociado con el establecimiento de un mundo ordenado. De esta manera y por medio del sacrificio, vemos no sólo el cosmos ordenado al Este, Oeste, Norte y Sur; pero vemos también el paraíso creado, el inframundo, la tierra y el cielo; y también el cosmos de flores, acuático, animal y de aves. Así mismo, la narrativa artística mural, como también su misma composición, sirven para establecer paralelos entre la acción divina y la de la realeza, reforzando la conexión entre el centro del mundo, la civilización, el maíz y el rey. Todo esto fue utilizado en San Bartolo para legitimar a un rey histórico, quien liga su legitimidad no a sus ancestros sino a su asociación directa con lo divino.

Palabras Clave: San Bartolo, murales, orden cósmico, orden social, legitimidad.

\section{Abstract}

During the Late Preclassic, San Bartolo, already had many of the characteristics expected from a large Classic Period center; well differentiated residential hierarchy and monumental ceremonial spaces clearly defined, as well as polychrome narrative murals and painted hieroglyphic texts. The mural scenes at San Bartolo bring to mind elements of the Codex Fejervary-Mayer as well as the Codex Borgia. In all 
cases, divine sacrifice is associated with the establishment of an orderly world. In this manner and through sacrifice, we see the order of the cosmos to the East, West, North and South; but also a paradise created, the underworld, the earth and the sky; and also a cosmos of flowers, aquatic, animal and of birds. Likewise, the mural artistic narrative, as well as its own composition, serves to establishing parallels between the divine action and the royal one, reinforcing the connection between the center of the world, civilization, maize and the king. All of this was used in San Bartolo to legitimize a historic king, linking his rightfulness to his direct association with the divine instead of ancestry.

Keywords: San Bartolo, murals, cosmic order, social order, legitimacy.

William A. Saturno (saturno@bu.edu), Universidad de Boston (Boston University). 


\section{INTRODUCCIÓN}

Las investigaciones que se han llevado a cabo desde mediados de los 1970s han cambiado dramáticamente nuestras ideas con respecto al tamaño y la complejidad de los centros mayas Preclásicos de las Tierras Bajas. Ahora se sabe que rasgos como ceremonias formales, especialización artesanal y urbanismo ya estaban bien establecidos en las Tierras Bajas en el período Preclásico. No obstante, en varios casos, estas asociaciones se han obtenido con mucha dificultad, pues los materiales preclásicos a menudo estaban enterrados a gran profundidad debajo de construcciones posteriores (Ringle 1999: 183). Éste fue el caso con los primeros descubrimientos de arquitectura monumental, fechada al Preclásico Tardío, en Uaxactún (Ricketson y Ricketson 1937) así como también con materiales posteriores, encontrados debajo de la Acrópolis Norte en Tikal (W. R. Coe 1965). Unos pocos sitios, como Cerros (Robertson y Freidel 1986; Scarborough 1991), Cuello (Hammond 1991), Komchén (Andrews V y Ringle 1992) y El Mirador (Dahlin 1984; Matheny y Matheny 1990), estaban en gran medida libres de la sobrecarga que impedía ver los patrones tempranos de su organización comunitaria. Sin embargo, los modelos tradicionales para el desarrollo de la civilización maya han surgido después de décadas de investigación arqueológica en sitios que ilustran trayectorias de evolución gradual en las cuales las descripciones de arquitectura y de artefactos del Preclásico como "más simples", "formativos" y "en desarrollo" llevaban consigo claras implicaciones evolutivas (i.e. Smith 1937: 3; Coe y Coe 1956: 372).

Esto, junto con abundantes y espectaculares restos del período Clásico, alentó una tendencia en el sentido de que la civilización maya se desarrolló en las Tierras Bajas pero ya para el año 300 D.C., mucho más tarde que sus contrapartes en las Tierras Altas, sugiriendo orígenes externos, además de haberse desarrollado en forma paulatina. Thompson sugería:

"Una zona tan aislada como el Petén difícilmente hubiese atestiguado los comienzos de la civilización maya, los que pueden esperarse más bien en partes del área maya donde el estímulo del contacto con otras culturas hubiese aligerado el desarrollo-Chiapas central parece ideal (Thompson 1954: 50)." 
El trabajo en la Acrópolis Norte de Tikal fue quizá el primero en retar estas nociones porque a medida que excavaban más profundo, "la elaboración y la apariencia Clásica de las estructuras descubiertas era aparente." De hecho, las cosas no se miraban ni "más simples", ni "más crudas", ni más "formativas" (Coe y McGinn 1963: 26). Más recientemente, las investigaciones en la "Cuenca Mirador" han revelado abundantes restos arquitectónicos del Preclásico Medio y Tardío y otras manifestaciones de una sociedad compleja. De hecho, algunas de las construcciones más grandes en Mesoamérica provienen de este tiempo y de esta región y los reconocimientos de asentamientos en varios sitios han descubierto ocupaciones del Preclásico Tardío eclipsando densidades del Clásico Temprano y Tardío (Hansen 1998). Además, investigaciones recientes han conducido a una mayor apreciación en cuanto a la sofisticación y antigüedad del ritual maya temprano, de sus deidades y de su arte (i.e. Bauer 2005; Fields 1991; Freidel 1990; Freidel y Schele 1998; Laporte y Fialko 1990, 1995; Hammond 1999; Hammond, Clarke y Estrada Belli 1992; Ringle 1999; Saturno et al. 2005). No obstante, existen prejuicios y la evidencia que se opone a los modelos tradicionales a menudo se puede tomar como simplemente epifenomenal. Es difícil considerar a El Mirador como representativo. Su simple tamaño de inmediato ilustra su ejemplar naturaleza urbana que no se parece a ninguna otra cosa que se haya encontrado en las Tierras Bajas. Es una muestra de uno y decididamente no es promedio.

El sitio de San Bartolo comparativamente parece más común. Tiene solamente unas pocas estructuras realmente monumentales, dando una clara indicación de cierto grado de complejidad, pero el sitio queda muy chico frente a la masa estructural de El Mirador. A pesar de su reducida extensión geográfica, ya en el Preclásico Tardío, San Bartolo poseía muchas de las características que se esperaría encontrar en un centro grande del Período Clásico, específicamente, una jerarquía residencial bien diferenciada y espacios ceremoniales monumentales claramente definidos. Aun más, sus murales narrativos policromados y los textos jeroglíicos pintados, en gran medida resuelven lo que en un tiempo fue la lamentada escasez tanto del agente ausente en el arte del Preclásico de las Tierras Bajas como también "la ausencia de un mecanismo para asegurar la transmisión estable del liderazgo central a través de las generaciones" que por mucho tiempo impidieron las discusiones sobre las instituciones de gobierno en desarrollo (Freidel y Schele 1988: 550). 


\section{ARTE MURAL}

A los mayas clásicos se les conoce ampliamente por sus diestros vasos policromados y los pocos murales que sobreviven indican que la pintura narrativa no se limitaba a objetos pequeños portátiles sino que también aparecían en paredes con estuco en composiciones elaboradas con brillantes policromos. En contraste con el formato comparativamente limitado que proveen los vasos o monumentos de piedra, las superficies de paredes proveen un espacio prácticamente infinito para la narrativa artística. Descubiertos en 1946, los murales de la Estructura 1 en Bonampak, Chiapas, son en mucho los murales más famosos conocidos para el Clásico maya (Ruppert et al. 1955). Los tres cuartos de la Estructura 1 han proporcionado conocimientos profundos únicos para el entendimiento de la vida cortesana, ritos, guerra y astronomía del Clásico maya (Lounsbury 1982; Miller 1986; Staines Cicero 1998). Para el período Clásico Temprano (250-600 d.C.), se sabe de murales en Tikal, Uaxactún y Río Azul, apareciendo tanto en las paredes de templos como en tumbas pintadas (Coe 1990: figura 175; Laporte y Fialko C. 1990: figuras 3.18-3.21; Smith 1950: figuras. 45-47; Adams 1999). Pero a pesar de que se conocen muchos murales de los mayas del Clásico, mucha de nuestra comprensión sobre el arte y la iconografía mayas del Preclásico Tardío viene de la escultura en estuco sobre edificios y bajo relieve en piedra, viniendo la mayoría de estos últimos de las Tierras Altas de Guatemala y de la región vecina costera del Pacífico. La escultura en piedra de Kaminaljuyú, Abaj Takalik, Izapa y otros sitios del Preclásico Tardío es fuertemente curvilínea y trae a la mente una tradición de pintor. Sin embargo, para el período Preclásico Tardío, se conocen pocas escenas pintadas ya sea en cerámica o en murales. Las máscaras de estuco de la Estructura $5 \mathrm{C}-2^{\mathrm{a}}$ en Cerros, Belice, están pintadas elaboradamente, pero este policromo está limitado a ornamentar la escultura de estuco (ver Freidel 1985). En Tikal, las excavaciones en la Acrópolis Norte revelaron pinturas murales del Preclásico Tardío en las paredes de la Estructura 5D-Sub.10-1era. y en el Entierro 166, pero desafortunadamente en ambos casos los murales estaban pobremente conservados (ver Coe 1990: figuras 32, 34).

Sin duda, los recientemente descubiertos murales de San Bartolo constituyen el corpus más importante de escenas pintadas conocidas para el período Preclásico Tardío maya. Hasta la fecha se ha expuesto aproximadamente 15 metros de la superficie mural, revelando más de 40 figuras en interacción. No solamente están bien conservados los muros, sino que también son de calidad excepcional tanto en 
cuanto a composición como en cuanto a la habilidad de la ejecución. Brillantemente pintados en una rica cantidad de colores, los murales son extremadamente refinados y detallados y ofrecen una oportunidad sin paralelos para evaluar qué tan temprano los reinos de las Tierras Bajas mayas utilizaron las bellas artes tanto para representar como para definir su lugar en el mundo físico y metafísico que los circundaba.

Hasta marzo del 2001, los arqueólogos no conocían las ruinas de San Bartolo, resultando esto en que la mayoría de las estructuras habían sufrido muchos años de excavación ilegal por los huaqueros. San Bartolo se caracteriza mejor como un centro maya pequeño cuyas fases de construcción monumental se concentraron en el período de 400 A.C. al 100 D.C.

En el registro palinológico, hay varias indicaciones de que el área alrededor de San Bartolo era mucho más húmeda durante su ocupación principal (Dunning 2006, comunicación personal). Árboles, agua, cal y lodo así como también alimentos para mantener a los labradores y artesanos debieron haber sido abundantes, dada la explosión de edificios que dio inicio en el siglo IV A.C. Con base a la reducción del grosor de las capas en las superficies revocadas y al abandono general del sitio para este tiempo, es evidente que los mayas redujeron estos recursos locales para el siglo I D.C.

El sitio, localizado en una región actualmente deshabitada en la parte noreste del Departamento de Petén, Guatemala, cubre un área aproximada de $1 \mathrm{~km}^{2}$ y se compone de más de 130 estructuras de piedra, organizadas alrededor de cuatro grupos arquitectónicos principales. El más grande de los grupos está asociado con la pirámide, Estructura No. 20, designada Las Ventanas, debido a las ventanas de albañilería conservadas en la superestructura de la fase final. El grupo consiste de un gran número de montículos residenciales, una estructura de "palacio", una plaza central grande y un pequeño campo de pelota, posiblemente formando el centro administrativo de la población Preclásica creciente de San Bartolo. Además, un camino empedrado lleva desde el extremo sur de la plaza central y se extiende por más de 200 metros hacia la cantera de piedra de cal y hacia un área pantanosa de temporada hacia el sur.

Un segundo grupo arquitectónico, Las Pinturas, llamado así por un grupo de pinturas que se encontró en su interior, se ubica aproximadamente a unos 500 metros al este de Las Ventanas y mirando hacia el oeste. La estructura central, la Estructura 
No. 1, parte de un grupo trino, tiene más de 26 metros de alto y está agujereada por numerosas excavaciones de huaqueros, de las cuales las más grandes se concentraron en la parte posterior. La excavación principal de los huaqueros comenzó como una trinchera axial en la subestructura de la fase final. Sin embargo, después de haber encontrado la terraza basal conservada, los huaqueros iniciaron la apertura de túneles. El túnel este-oeste de los huaqueros continúa por más de 40 metros hacia el oeste, ocasionalmente con ramales tanto hacia el norte como hacia el sur, buscando tumbas en vano. Actualmente son evidentes por lo menos siete etapas de construcción, de las cuales, por medio de radiocarbono y de la evidencia cerámica, todas fechan al Preclásico. El episodio final de la construcción acabada comenzó en los últimos años del siglo I A.C., cuando las penúltimas construcciones en el grupo fueron rellenadas para así obtener una base estable para la Estructura 1. Durante el 2006 se descubrieron restos de construcción adicional en la base de la Estructura 1, donde se habían iniciado los comienzos de una plataforma extendida, pero ésta nunca llegó a la primera terraza.

Para interpretar el significado del mural, entender su contexto arquitectónico es tan importante como entender la imaginería. El edificio que contiene los murales fue una de múltiples estructuras que se añadieron detrás del amplio complejo ceremonial, ahora conocido como Las Pinturas, como parte de su penúltima fase de construcción completada. Pinturas Sub-1, tal como originalmente se le designó al cuarto de los murales, es un edificio rectangular de albañilería, construido sobre una plataforma baja $(60 \mathrm{~cm})$ roja. Las paredes exteriores verticales se elevan 1.5 metros y estaban decoradas con figuras humanas pintadas, entre volutas rojas arremolinadas en las esquinas del edificio y alrededor de sus cinco puertas. Sobre las paredes verticales comienza una cornisa y una fachada ligeramente angulada de relieve en estuco pintado y modelado de un poco más de un metro de alto. Esta fachada en la actualidad se conserva solamente en el lado norte de la estructura, aunque seguramente se habría extendido también hacia sus lados este y sur, cuando el edificio estuvo en uso. La entrada principal al edificio era desde su lado este, donde una única grada se levanta enfrente de la puerta central de 2.6 metros de ancho. Dos puertas más pequeñas (1.3 metros) estaban ubicadas a ambos lados de la puerta principal, un poco después de la extensión de la grada. Además, otras dos puertas estaban ubicadas en la parte trasera del edificio, en sus esquinas noroeste y suroeste. Todas las cinco puertas son relativamente bajas (1.4 metros), significando esto que el maya de estatura promedio muy seguramente habría tenido que agacharse para entrar al espacio. 
El interior se caracteriza por paredes verticales revocadas que se yerguen hasta una altura de 1.4 metros, antes de internarse en el punto donde se esperaría encontrar el comienzo de un arco. Sin embargo, ante la ausencia de un arco, las paredes continúan subiendo verticalmente, aproximadamente un metro hasta el techo. El comienzo, o moldura mediana, visualmente divide el cuarto en mitades verticales. La parte debajo de la moldura está pintada en rojo y más abajo se extiende por las paredes alrededor una banda celeste geométrica y sobre ésta se extiende la narrativa del mural.

Durante la temporada de campo del 2005 y al norte de Pinturas Sub-I, se descubrió un segundo edificio contemporáneo, forzándonos a una re-designación del cuarto mural original como Pinturas Sub-IA y al nuevo edificio se le llamó Pinturas SubIB. Pinturas Sub-IB fue también en su mayoría desmantelado durante el episodio de la misma construcción que enterró a Sub-IA, de hecho solamente queda el lado oeste del edificio. Sin embargo, de lo que ha quedado se pueden hacer algunas comparaciones importantes con su vecino mejor conservado. Sub-IB fue una estructura de dos cuartos, puesto sobre una plataforma roja de 1.5 metros con máscaras de estuco a los lados de su única gradería al lado sur. Su exterior, así como el de Sub-IA, estaba decorado con figuras humanas y volutas rojas en sus esquinas, pero con el agregado de una banda celeste exterior, circulando el edificio debajo de la cornisa. Cualquier decoración de estuco modelado, si la hubo, fue destruida durante el entierro del edificio. El espacio interior se dividió en dos cuartos, al de atrás se llegaba subiendo una grada interna pintada en rojo que remedaba la forma de la plataforma exterior. Las paredes están bien conservadas y no están pintadas, exceptuando la parte debajo de la moldura medial, la que, así como en Sub-IA, está pintada en rojo. Todo el revocado sobre la moldura medial fue removido antes del entierro. No obstante, el predominio de fragmentos de murales pintados por manos diferentes durante el relleno de la fase de construcción final aumenta la posibilidad de que la Sub-IB pudo haber estado decorada también con murales interiores.

La orientación de la Sub-IB y su relación con la Sub-IA dan pie a la intrigante posibilidad de que una tercera estructura (¿Sub-IC?) se localice más al sur, parcialmente encerrando una plaza pequeña enfrente de la Sub-IA. Con o sin la presencia de una tercera estructura, las estructuras Sub-IA y B forman un área ceremonial más o menos restringida, distinta del lado frontal público de la plataforma "Yaxché", donde se eleva la Pirámide Pinturas principal, como el edificio central en un grupo triduo. Una escalinata que se encontró en la esquina trasera (noroeste) de la plataforma "Yaxché" puede que provea el medio de conectar los 
ritos relativamente privados del complejo de murales con aquellos despliegues más públicos que se llevaban a cabo al frente de la pirámide.

El edificio de murales (Pinturas Sub-IA) se remató directamente en la cara este (detrás) de la plataforma "Yaxché" y ésta ubicación seguramente contribuyó a la vida truncada del uso del cuarto e irónicamente al mismo tiempo contribuyó a la preservación del mural. Visto desde el exterior, el edificio fue diseñado para no tener una pared oeste, sino más bien para integrar sus paredes norte y sur directamente con la base en declive de la plataforma "Yaxché". Esto no era perceptible desde el interior del cuarto, pues la pared interior vertical oeste ocultaba el frente de la plataforma detrás de su albañilería delgada y su revestimiento de estuco, uniendo en ángulos rectos el interior de las paredes norte y sur. No obstante, el peso del relleno entre la plataforma en declive y la pared interior oeste no era sostenible estructuralmente, deslizándose en el declive hasta donde a su componente horizontal se le dirigió de nuevo en la base de la pared interior oeste. Allí comenzó a minar la estabilidad de la pared delgada, causándole hendiduras y obligándola a arquearse marcadamente hacia el espacio interior. Grandes porciones del revocado de la parte baja de la pared oeste se habían ya desprendido de la albañilería debajo y habían sido removidas de la estructura antes de que fuese rellenado el cuarto.

El techo plano del edificio pudo haber sido otro factor que contribuyese a la destrucción de la estructura. A partir de las áreas con daños de agua y con aumento de carbonato de calcio y que preceden la destrucción del cuarto, está claro que el agua repetidas veces penetró el techo. Además, el espacioso interior (4.2 $\mathrm{x}$ 9.5 metros) de la estructura de un solo cuarto fue el resultado de la utilización de cinco vigas grandes horizontales orientadas norte-sur para sostener la mayoría de la carga de la albañilería del techo plano. Los cinco huecos para las vigas se ven claramente a lo largo y sobre el mural oeste tanto donde el revocado de la pared se abulta hasta el punto donde habrían estado las vigas como también por la diferencia de material de relleno presente en los huecos. Cuatro de las vigas del techo habrían resistido fácilmente, una en cada lado de las puertas norte y sur, respectivamente, pero la carga que llevaba la viga central del techo habría sido soportada directamente sobre la puerta central ancha, posiblemente trayendo así más complicaciones estructurales.

Las cinco puertas del cuarto de murales y el plano abierto del piso permiten diversas maneras de ver y de interactuar con la narrativa pintada y, aunque en términos de su organización el mural "se lee bastante similar a un códice abierto" (Taube et al. s.f.), no está claro dónde encontrar el inicio de la historia. Concebiblemente uno podría entrar y salir por la puerta central, siguiendo un circuito por todo el cuarto tal como 
se mueven las manecillas del reloj 0 al contrario, tan fácilmente como uno también podría entrar desde la esquina suroeste y salir por la esquina noroeste, habiendo así caminado solamente a lo largo de la pared oeste. Los artistas consistentemente produjeron divisiones en la narrativa completa, desplegando caracteres individuales espalda con espalda y creando así cortes visuales en el programa pintado, donde los participantes en el mismo segmento narrativo o están frente a frente 0 tienen un protagonista común. Esto tiene el efecto de enfocar el ojo del observador hacia el centro de un segmento, definiendo claramente sus límites. Sin embargo, a pesar de la utilidad de esta convención para identificar escenas individuales, la misma es menos útil para establecer la secuencia más amplia de la pieza en su totalidad. Existen diez ocasiones, en la porción conservada del mural, de individuos espalda con espalda, creando once escenas individuales de extensión y complejidad variadas. Aunque se pueden encontrar algunas asociaciones entre escenas, con base a la presencia repetida de individuos, la relación específica secuencial entre escenas es más difícil de establecer con algún grado de certeza.

En otro lado, la narrativa del mural se ha presentado de manera básicamente lineal, yendo de izquierda a derecha, tanto como una función de nomenclatura (las figuras que aparecen en el mural están numeradas y descritas de izquierda a derecha) y también como una posible interpretación del orden de lectura proyectado (Saturno 2006; Saturno et al. 2005; Taube et al. s.f.). La interpretación que aquí continúa se basa en la sintaxis visual tanto lineal como concéntrica (Freidel 1985; Freidel y Schele 1988) para así poder presentar una visión alterna. Debe mencionarse al inicio, no obstante, que la evidencia iconográfica específica para la identificación de personajes individuales en la narrativa se discute más a profundidad en otras publicaciones (e.g., Saturno et al. 2005; Taube et al. s.f.) y solamente se le tocará muy brevemente en las descripciones siguientes.

Al entrar por la puerta principal del edificio, lo primero que el espectador ve es la pared oeste. En lo alto y exactamente en el centro de esa pared, la viga central del techo penetra la superficie pintada directamente entre la Deidad Principal del Pájaro que mira hacia el sur, tal como primeramente lo identificó y lo nombró Lawrence Bardawil (1976) y el dios del maíz que mira hacia el norte, reforzando el corte visual que establece su posición de espalda a espalda. Directamente debajo de la viga, tres pájaros, con volutas de canto saliendo de sus picos, vuelan hacia la izquierda, alejándose de la espalda del dios del maíz, enfatizando aun más la división. Moviéndose hacia la izquierda, la Deidad Principal del Pájaro es el foco de la narrativa, apareciendo cinco veces a lo largo de la mitad sur de la pared. Movilizándose hacia la derecha, quien disfruta el papel principal es el dios del maíz, 
apareciendo también en repetidas ocasiones. De manera que, al entrar al cuarto y en su línea central, el espectador inmediatamente confronta la decisión que afecta la historia que se está contando y es posible que en distintas épocas se hayan hecho diferentes elecciones. Para fines de esta presentación, seguiré los pájaros hacia el sur, antes de regresar a la línea central y tomar la narrativa del dios del maíz.

\section{Centrando el Mundo}

La mitad sur del mural de la pared oeste ilustra una visión del cosmos maya en la cual cuatro escenas muy similares demuestran a un Señor Joven, parecido al Hun Ahaw del período clásico o al Hunahpú maya K'iché del Siglo XVI, ocupado en el sacrificio de sangre, ante la Deidad Principal del Pájaro, posando en un árbol. Siguiendo a Karl Taube (Taube et al. s.f.), la presencia repetida de estos individuos realizando actos similares de sacrificio seguramente indica el continuo despliegue de las direcciones del mundo como comúnmente se ve en representaciones mesoamericanas del génesis del cosmos. Las escenas en San Bartolo traen a la mente tanto la página 1 del Códice Fejervary-Mayer, en donde el desmembrado Tezcatlipoca es tirado sangrando a los árboles en las cuatro esquinas del mundo y también recuerdan las páginas 49-53 del Códice Borgia, en las cuales los árboles del mundo nacen de los cuerpos de las diosas sacrificadas. En todos los casos, el sacrificio divino está asociado con el establecimiento de un mundo ordenado.

La versión de San Bartolo comienza con el surgimiento, desde una viga del techo y a lo largo de la orilla cimera del mural, de una banda celestial con cabeza hendida de serpiente. La Deidad Principal del Pájaro desciende desde el cielo hendido entre volutas de nubes oscuras. Inmediatamente debajo del monstruoso pájaro está la fecha $3 \mathrm{IK}$ dentro de un cartucho rojo goteando, muy similar en forma al de la Estela 10 de Kaminaljuyú. A la izquierda de la fecha, aparece un texto corto pintado, el cual muy posiblemente describe el evento.

Desafortunadamente, la forma temprana de esta escritura y el pobre estado de conservación no permiten descifrar los detalles. A la izquierda del texto, una figura como enana, con pico de pato y bailando, hace un gesto hacia arriba, hacia el pájaro descendente. Una línea negra delgada, como las volutas de canto de los tres pájaros detrás de esa figura, da vuelta sobre la figura, muy posiblemente indicando que él también está cantando y quizá aun llamando a la Deidad Principal del Pájaro para que baje desde el cielo. A medida que la escena continúa hacia la izquierda, 
la Deidad Principal del Pájaro se posa en el primero de los cuatro árboles cuyas ramas se extienden bajo su gran peso.

Aquí vemos al pájaro en su forma más resplandeciente, cubierto con joyas y, en sus enormes talones, él toma la fruta redonda de calabaza del árbol y, en su monstruoso pico, lleva una serpiente bicéfala. Sus alas están giradas en direcciones opuestas, desplegando los símbolos k'in y ak'bal, día y oscuridad, junto con flechas de piedra entre sus plumas. Su árbol se levanta de un campo de flores perfumadas y su tronco torcido florece tanto con flores como con frutos, consistente con las concepciones mayas de un paraíso floral abundante y asociado con el este, donde el sol renace diariamente (Taube 2004).

La humildad de la vestimenta del Joven Señor contrasta con el resplandecimiento del gran pájaro mítico ante él y remeda la intrepidez de sus acciones en la escena. Con únicamente una faja de tela alrededor de su cintura, nudos en sus rodillas y tobillos, un collar tejido en su cuello, una banda de cabeza cruzada y una barba falsa sirviendo de marco para su cara, el Joven Señor está parado enfrente de la Deidad Principal del Pájaro. Parado en medio de las flores enfrente del árbol del mundo, él pasa una rama puntuda por su pene, soltando grandes chorros de sangre en quizá el más temprano y más gráfico despliegue de sacrificio de genitales en el mundo maya. Es un sacrificio que se repite tres veces más a medida que uno se mueve hacia el sur por la pared que sigue el descenso del pájaro mítico desde el paraíso floral del este hasta el reino acuoso del inframundo en el oeste.

En la siguiente escena, mucho del segundo árbol y del pájaro fue destruido en la antigüedad cuando los mayas construyeron una pared de retención para estabilizar el mampuesto que se utilizó para rellenar el cuarto, dejando solamente una de las alas de la Deidad Principal del Pájaro, sin el k'in ni el ak'bal, y su pico visibles. Todavía está claramente posando sobre un árbol, aunque el follaje es distinto, y todavía agarra en su pico una serpiente bicéfala. Sin embargo, una de las joyas, que llevaba sobre su ceja cuando descendía del cielo y se posaba en el primer árbol, se ve aquí suelta y flotando delante de él y con sangre emanando de su base, quizá dando la idea de la pérdida de posición que poco a poco va perdiendo el pájaro mítico como resultado de los sacrificios que ofrece el Joven Señor.

Para el segundo sacrificio, el Joven Señor no está entre flores sino que más bien aparece con sus pies flotando un poco sobre la línea del mural que da al suelo. Parado así en el aire, con un par de pájaros amarrados a una canasta de tejido en su faja, de nuevo ofrece su sangre en sacrificio, aunque esta vez está también acompañado de un pavo sacrificado. El pavo aparece doblado hacia atrás sobre un 
trípode de madera y tres piedras apiladas sobre su estómago abierto, emanando de allí volutas negras y rojas, remolineando hacia arriba hacia la Deidad Principal del Pájaro. La vestimenta del Joven Señor poco ha cambiado desde la primera escena, aunque sí lleva un elemento de estrella en su tocado que lo identifica con el texto corto pintado sobre y detrás de él, añadiendo quizá especificidad a los aspectos direccionales de la narrativa (Taube et al. s.f.).

La narrativa continúa con la Deidad Principal del Pájaro posando en las ramas del tercer árbol direccional, con sus alas ampliamente extendidas, pero con la serpiente bicéfala en su pico sin una de sus cabezas. La cabeza desmembrada flota cerca con sangre saliendo de ambos extremos del cuello cortado. El Señor Joven aparece parado delante del árbol, pero esta vez con sus pies firmemente en la tierra y un venadito afianzado en su faja. Su vestimenta y su método de sacrificio no han cambiado mucho, aunque ya no lleva nudos en sus rodillas y por primera vez aparece barba en su barbilla, la que sale por debajo de su barba falsa. Entre el Joven Señor y la Deidad Principal del Pájaro aparece un venado de sacrificio, de nuevo puesto sobre el trípode de madera, con tres piedras colocadas en su estómago abierto y volutas negras y rojas remolineando hacia arriba y al mismo tiempo cayendo sangre negra y roja.

El cuarto árbol nace de la cabeza sauria del monstruo terrestre con agua negra corriendo sobre las espinas de su lomo. La conservación limitada del mural en la esquina suroeste del cuarto restringe lo que se pueda decir acerca del estado de la Deidad Principal del Pájaro, pues solamente sus talones y su cola se conservan entre el follaje del último árbol. De la misma manera, solamente la única cabeza de la anterior serpiente bicéfala se conserva y únicamente los pies del Joven Señor son visibles, esta vez cubiertos con grandes manchas negras. Detrás de él, apenas puede reconocerse la aleta de un pez, posiblemente amarrada a su cintura, pero lo que sí está claro es que la cuarta ofrenda de auto sacrificio se realiza en el agua y está acompañada de un pescado colocado sobre el trípode. En esta situación, cinco piedras se han apilado encima del pescado que está sobre su lomo y volutas rojas y negras suben, pero poca, si es que hay alguna, sangre sale del pescado mismo.

Es de interés que un grupo de once fragmentos de mural, con una pátina similar hasta la esquina suroeste del cuarto del mural, se descubrieron en excavaciones entre Pinturas Sub-IA y Sub-IB, que representan las piernas y los brazos manchados del Joven Señor acuoso. Sostiene la rama de su árbol en su mano, pero no está realizando un auto sacrificio y, más importante, él lleva a la Deidad Principal del 
Pájaro pegada a su espalda, dando pie a la intrigante posibilidad que la derrota final del pájaro mítico haya tenido lugar en lo que seguía de la narrativa en el ahora destruido mural de la pared sur.

Inmediatamente después de ver el mural de la pared oeste ya excavada, Taube notó la similitud extraordinaria, a pesar de estar separadas por aproximadamente 1500 años, entre la narrativa de las pinturas y aquella de las Páginas de Año Nuevo (págs.. 25-28 ) del Códice de Dresde, las que ilustran la instalación de cuatro árboles direccionales del mundo, acompañados por el esparcimiento de sangre y ofrendas de incienso por el este, pavo por el sur, venado por el norte y un pez en el agua (Taube et al. s.f.).

Las cuatro escenas de San Bartolo no sólo ilustran la organización del mundo por medio de la creación de las cuatro direcciones cardinales, pero quizá también ilustran otras taxonomías mayas de cuatro partes. Los sacrificios toman lugar primero en un campo de flores en el paraíso floreado, íntimamente asociado con el este, seguido por sacrificios en el aire, en el suelo y en el agua, a menudo asociados con el inframundo y con el oeste. Además, los sacrificios mismos demuestran una división cuadripartita de clases de mantenimiento donde pueden verse flores fragantes como la "'comida' simbólica de dioses y ancestro", mientras que el pavo, el venado y el pescado pueden entenderse como comidas del cielo, del bosque y de los arroyos (Taube et al. s.f.: 19).

De esta manera y por medio del sacrificio, vemos no sólo el cosmos ordenado al Este, Oeste, Norte y Sur; pero vemos también el paraíso creado, el inframundo, la tierra y el cielo; y también el cosmos de flores, acuático, animal y de aves.

En el pensamiento tradicional maya, los árboles alrededor del mundo de cuatro lados reflejan el espacio social construido del templo, la plaza, la casa y el campo en completo contraste con el crecimiento caótico del bosque salvaje (Taube 2003). De esta manera, el Joven Señor, por medio de su sacrificio, organiza el cosmos alrededor de la apropiciación y quizá la humillación por partes del símbolo preeminente del salvaje sobrenatural, la Deidad Principal del Pájaro, en una manera relacionada con las versiones contemporáneas, Clásicas y Postclásicas de Hun Ahaw/Hunahpú, tirándole a este monstruoso pájaro para quitarlo del camino. Por extensión, los reyes mayas recuerdan esta conquista por medio de la expansión de sus dominios hasta las cuatro esquinas de la misma manera que el campesino maya lo hace por medio de la construcción de su casa y de su campo. 


\section{Centrando al Rey}

Movilizándose hacia el norte desde la línea central del cuarto, nos encontramos con una composición muy diferente. En vez de una progresión lineal de escenas repetidas en las cuales solamente ciertos detalles cambian, al espectador se le presenta una serie de narrativas concéntricas que involucran el ciclo del maíz y la coronación de reyes. Debido a este arreglo concéntrico, en vez de describir las escenas de izquierda a derecha o de derecha a izquierda, me esforzaré para moverme del centro hacia fuera, enfatizando la serie de pares concéntricos.

Comenzaremos por el centro mismo de la composición, con el dios maya del maíz bailando y tocando música dentro de la tierra-tortuga de cuatro lóbulos. El dios del maíz toca un tambor de concha de tortuga, suspendido de su cuello con la pata talonada de un pájaro, mientras levanta su otra mano para tocar el siguiente paso. La relación simbólica entre el tambor de concha de tortuga, la lluvia y el trueno, tal como lo anotó Ëduard Seler (1990-1998, V: 281) y en la cual "la concha de tortuga es un tambor natural...el trueno el tambor celestial" se refuerza con la audiencia del dios del maíz de dioses mayas del agua. A su izquierda, Chaak, el dios de la lluvia, está sentado con la pierna cruzada en un trono de piedra, escuchando con su mano extendida, mientras que a su derecha el dios del agua terrenal hace gestos similares desde su colchón (Taube 1992: 56-59; Taube et al. s.f.). La escena completa se lleva a cabo dentro del motivo de cueva de cuatro lóbulos, quizá mejor conocido por la escultura en relieve de la era olmeca en Chalcatzingo, en la cual ambos lados lobulados de las cuatro partes enmarcan simétricamente la acción y designan su ubicación como dentro de la tierra. Que la tierra se localiza dentro de la tierra en forma de tortuga se demuestra colocando patas con uñas en las cuatro grietas en el exterior lobulado, acompañado de una cabeza prominentemente encorvada y extendiéndose hacia la izquierda en una corriente ondulante de agua.

Imágenes del dios del maíz saliendo desde dentro de la tierra en forma de tortuga son comunes en el arte clásico maya (ver por ejemplo a Robiscek y Hales 1981; Taube 1985, 1988). Aquí, en una de las más tempranas y de las más explícitas versiones de este episodio mítico, el dios del maíz lleva una cesta en su espalda, retenida por un mecapal en su frente, sugiriendo que lleva consigo la cosecha de maíz mientras sale de la tierra bailando (Taube et al. s.f.: 50 ). Es importante anotar que esta parte del mural fue intencionalmente borrado antes de su entierro, pues los golpes repetidos de un hacha de piedra están todavía visibles en el revocado del mural, abriendo físicamente la caparazón de la tortuga para simbólicamente permitir que salga la cosecha de maíz. 
En ambos lados de la tortuga tenemos imágenes pares del dios del maíz. A la izquierda se le mira al momento de su nacimiento, como un infante llevado en los brazos de otra deidad, cruzando a pasos largos por el agua. El infante dios del maíz, cuya apariencia se parece mucho a las versiones olmecas de la misma deidad, se identifica claramente por su cráneo sinuoso, su ojo sesgado, su labio superior pronunciado y su colmillo curvo (Taube 1996). A la derecha aparece al momento de la muerte, una culebra enrollada en su cintura y zambulléndose en la corriente negra de agua. El ciclo del maíz, su metafórico nacimiento, muerte y surgimiento del centro la flor de cuatro lóbulos de la tierra-tortuga como la cosecha, ocupa así la porción central de la composición y provee un interesante contraste con las escenas del sur, donde aparece la creación en cuatro partes de un cosmos ordenado. Los límites del espacio civilizado y simbolizados por bosque y habitado por bestias míticas, son distintos del centro donde el orden depende tanto literal como metafóricamente del ciclo de la agricultura.

Moviéndose de nuevo otra vez hacia fuera, vemos un par de coronaciones y dos escenas ilustrando el papel que juegan los reyes coronados como el centro del mundo. A la izquierda, el dios del maíz, elaboradamente vestido con polainas de piel de jaguar, está sentado sobre un andamio de madera, tapizado con cuero de jaguar. Tres hachas de jade y de faja y un jaguar sacrificado cuelgan suspendidos de un árbol colocado sobre el andamio detrás del dios sentado. Enfrente del andamio, el dios del maíz, con la misma vestimenta, incluyendo un gorro con plumas y la cola de un pájaro, se pasa a sí mismo la cabeza laminada de la Deidad Principal del Pájaro como su joya de coronación.

A la izquierda del andamio, se ve al dios del maíz de nuevo con la misma vestimenta que en su coronación, con una lanza en su mano ofreciendo un sacrificio desconocido (erosionado), completando la creación del mundo de cuatro lados por medio del establecimiento del centro del mundo en la forma del quinto árbol. Este árbol es diferente de los otros cuatro en la mitad sur de la pared oeste ya que sus ramas están hacia arriba, sin el peso de la Deidad Principal del Pájaro, carga solamente a un simple tucán. Estableciendo el centro del mundo amansado, el dios del maíz refuerza la noción que el centro del mundo está gobernado por el orden y ese orden se fundamenta en la agricultura.

A la derecha del ciclo del maíz, se ve una coronación paralela, seguramente demostrando a un rey humano. El rey está sentado sobre un cojín bordado, el que está sobre un andamio de madera y con sus manos apretando un bulto sagrado. Detrás de él un símbolo tejido como petate y un jaguar sacrificado cuelgan de un árbol sobre el andamio. Enfrente del andamio, un sirviente, con un tocado en forma 
de pájaro y una capa elaboradamente tejida, sube una escalera para colocar una corona en forma de trébol sobre la cabeza del rey. Entre las dos figuras, un texto pintado que termina en AHAW posiblemente provee el título completo del rey.

Detrás del andamio, realmente en la pared norte del cuarto, se ve el nacimiento de cinco niños de una calabaza explotando (para una descripción más completa, ver Saturno et al. 2005). Es importante que el individuo saliendo del centro de la calabaza lleva el mismo casco y la misma faja que el rey sentado sobre el andamio, demostrándolo como el centro de un nacimiento mítico cuadripartito, bastante similar a la manera en que el dios del maíz aparece centrando la creación de cuatro partes en el quinto árbol. De esta manera, la narrativa artística, como también su misma composición, sirven para establecer paralelos entre la acción divina y la de la realeza, reforzando la conexión entre el centro del mundo, la civilización, el maíz y el rey. A esta conexión se le da importancia adicional por medio del uso de símbolos como el dios del maíz que se extiende hacia atrás al pasado distante por medio de la similitud iconográfica con civilizaciones más antiguas.

\section{Centrando el Reino}

Pinturas adicionales se han encontrado por todo el complejo Pinturas. Los restos colapsados del templo de la fase final contienen, sobre la plataforma "Yaxché", tanto fragmentos interiores pintados como estuco exterior modelado y pintado. A lo largo del lado frontal de la pirámide, contemporánea con los murales de la Sub-IA, se descubrió un escondite de unos 8,000 fragmentos de mural interior. Ensanchando más los túneles dentro del complejo Pinturas ha llevado al descubrimiento de otros edificios con decoración pintada que sustancialmente anteceden a los murales de Pinturas Sub-IA (Saturno et al. 2006). Un ejemplo de esta pintura más temprana viene de la fase Sub-V del edificio, la que se fecha a la parte temprana del siglo III o a la parte tardía del siglo IV A.C. e incluye tanto un texto jeroglíico así como al dios del maíz. Es interesante que el estilo del texto es dramáticamente diferente del que se encontró en Pinturas Sub-IA, mientras que la iconografía del dios del maíz ha cambiado poco durante ese mismo tiempo.

Excavaciones fuera del complejo Pinturas en San Bartolo no han descubierto evidencia de edificios pintados. De hecho, parece que a la estructura ceremonial más grande del sitio, Las Ventanas, no se le aplicó pintura a lo largo de sus aproximadamente 500 años de construcción continua. Así que, el complejo Pinturas, aunque no representa la arquitectura más imponente del sitio, pudo habérsele tomado como el centro ceremonial del sitio durante toda la larga ocupación del 
mismo, continuamente decorado con símbolos de fertilidad de la agricultura y asociado con la misma noción de gobierno en el sitio.

Todo esto fue utilizado en San Bartolo para legitimar a un rey histórico, con nombre y título. Es interesante que si vemos el mejor ejemplo conocido de un mural maya, vemos la legitimación histórica del heredero al trono de Bonampak, tarde en el siglo VIII D.C. Todos los eventos históricos en Bonampak aparecen debajo de una banda celestial geométrica sobre la cual se sientan varias deidades y constelaciones. Pero en San Bartolo toda la acción toma lugar sobre la banda celestial en el reino de los dioses, incluyendo la coronación del rey histórico quien liga su legitimidad no a sus ancestros sino a su asociación directa con lo divino.

\section{BIBLIOGRAFIA}

- Adams, R. E. (1999). Río Azul: An Ancient Maya City. Norman: University of Oklahoma Press.

- Andrews E.W., Ringle W.M. (1992). Los Mayas Tempranos en Yucatán: Investigaciones Arqueológicas en Komchén. Mayab, 5-17.

- Bauer, J. R. (2005). Between Heaven and Earth: The Cival Cahe and the Creation of Mesoamerican Cosmos. En V. Fields, D. Reents-Budet, Lords of Creation: The Origins of Sacred Maya Kingship (págs. 28-29). London: Scala.

- Coe, W. R. (1990). Excavations in the Great Plaza, North Terrace, and North Acropolis of Tikal. Tikal Report No.14, 6 vols.

- Coe W. R., Coe M.D.(1956). Excavations at Nohoch Ek, British Honduras. American Antiquity, 370-382.

- Coe W. R.,McGinn J.J. (1963). Tikal: The North Acropolis and an Early Tomb. Expeditions 5, 24-32.

- Dahlin, B. H. (1984). A Colossus in Guatemala: The Preclassic Maya City of El Mirador . Archaeology, 18-25.

- Fields, V. M. (1991). The Iconographic Heritage of the Maya Jester God. En M. G. Robertson, V.M. Fields, Sixth Palenque Round Table (págs. 167-174). Norman: University of Oklahoma Press. 
- Freidel, D. A. (1985). Polychrome Facades of the Late Preclassic Period. En E. H. Boone, Painted Architecture and Polychrome Monumental Sculpture in Mesoamerica (págs. 5-30). Washington: Dumbarton Oaks.

- Freidel, D. A. (1990). The Jester God: The Beginning and End of a Maya Royal Symbol. En F. S. Clancy, P.D. Harrison, Vision and Revision in Maya Studies (págs. 67-76). Albuquerque: University of New Mexico Press.

- Freidel D. A., Schele L. (1988). Symbol and Power: A History of the Lowland Maya Cosmogram . En E. P. Benson, G.G. Griffin, Maya Iconography (págs. 44-93). Princeton: Princeton University Press.

- Hammond, N. (ed.). (1991). Cuello: An Early Maya Community in Belize. Cambridge: Cambridge University Press.

- Hammond N., Clarke A., Estrada Belli F. (1992). Middle Preclassic Maya Buildings and Burials at Cuello, Belize . Antiquity, 955-964.

- Hansen, R. (1998). Continuity and Disjunction: The Pre-Classic Antecedents of Classic Maya Architecture . En S. Houston, Function and Meaning in Classic Maya Architecture (págs. 49-122). Washington: Dumbarton Oaks .

- Laporte J. P., Fialko C. V. (1990). New Perspectives on Old Problems: Dynastic references for the Early Classic at Tikal. En F. S. Clancy, Vision y Revision in Maya Studies (págs. 33-66). Albuquerque: University of New Mexico Press.

- Lounsbury, F. G. (1982). Astronomical Knowledge and Its Uses at Bonampak, Mexico. En A. Aveni, Archaeoastronomy in the New Wold (págs. 143-58). Cambridge: Cambridge University Press.

- Miller, M. E. (1986). The Murals of Bonampak. Princeton: Princeton University Press.

- Quenon M., Le Font G. (1997). Rebirth and Resurrection in Maize God Iconography . En J. Kerr, The Maya Vase Book, vol 5 (págs. 884-902). New York : Kerr Associates.

- Ricketson O. G.Jr., Ricketson E.B. (1937). Uaxactun, Guatemala. Carnegie Institutio of Washington Publicaction 477.

- Ringle, W. M. (1999). Pre-Classic Cityscapes: Ritual Politics among the Warly Lowland Maya. En R. Joyce, D.C: Grove, Social Patter s in Pre-Classic 
Mesoamerica (págs. 183-223). Washington : Dumbarton Oaks Research Library and Collection .

- Ringle, W. M. (1999). Pre-Classic Cityscapes: Ritual Politics among the Warly Lowland Maya. En R. Joyce, Social Patter s in Pre-Classic Mesoamerica (págs. 183-223). Washington : Dumbarton Oaks Research Library and Collection .

- Robertson R. A., D.A. Freidel (eds). (1986). Archaeology at Cerros, Belize, Central America vol. 1: An Interim Report. Southern Methodist University Press: Dallas.

- Robicsek F., D.M. Hales. (1981). The Maya Book of the Dead: The Ceramic Codex. Charlottesville: University of Virginia Art Museum .

- Ruppert, K., Thompson J.E.S., Proskouriakoff T. (1955). Bonampak, Chiapas, Mexico. Washington: Carnegie Institution of Washington.

- Saturno, W. A. (2006). The Dawn of Maya Gods and Kings. National Geographic, 68-77.

- Saturno W. A., Stuart D., Beltrán B. (2006). Early Maya Writing at San Bartolo, Guatemala. Science 311, 1281-1283.

- Saturno W. A., Taube K.A., Stuart D. (2005). The Murals of San Bartolo, el Petén Guatemala, Part 1: the North Wall. Ancient America 7.

- Scarborough, V. (1991). The Settlement System in a Late Preclassic Maya Community. En D. Freidel, Archaeology at Cerros, Belize, Central America III. Dallas: Southern Methodist University Press.

- Seler, E. (1990). Collected Works in Mesoamerican Linguistics and Iconography. En F. E. Comparato, Collected Works in Mesoamericann Linguistics and Iconography 6 Vols . Lancaster : Labyrinthos .

- Smith, A.L. (1950). Uaxactun, Guatemala: Excavations of 1931-1937. Washington: Carnegie Institution of Washington .

- Smith, R. E. (1937). A Study of Structure A-I Complex at Uaxactun, Peten, Guatemala. Contributions to American Archaeology No. 19, 189-231.

- Staines, C. (1998). La pintura mural prehispánica en México, II, Area Maya: Bonampak. Mexico City : Universidad Nacional Autónoma de México . 
- Taube, K. (1985). The Classic Maya Maize God: A Reappraisal . En M. G. Robertson, Fifth Palenque Round Table (págs. 171-81). San Francisco : Pre Columbian Art Research Institute .

- Taube, K. (1988). A Prehispanic Katun Wheel . Journal of Anthropological Research, 183-203.

- Taube, K. (1992). The Major Gods of Ancient Yucatan . Washington : Dumbarton Oaks.

- Taube, K. (1995). The Rainmakers: The Olmec and ther Contribution to Mesoamerican Belief and Rituals. En The Olmec World (págs. 83-103). Princeton: The Art Museum .

- Taube, K. (1996). The Olmec Maize God: The Face of Corn in Formative Mesoamerica. Anthropology and Aesthetics Vol. 29/30, 39-81.

- Taube, K. (2003). Ancient and Contemporary Maya Conceptions about the Field and Forest . En A. G. Pompa, Three Millennia at the Human-Wildland Interface (págs. 461-92). New York : Haworth Press.

- Taube, K. (2004). Flower Mountain: Concepts of Life, Beauty and Paradise among the Classic Maya. Anthropology and Aesthetics 45, 69-98.

- Taube K. A., Saturno W.A., Stuart D. (Sf). The Murals of San Bartolo, El Petén, Guatemala, Part 2: The West Wall . Ancient America 10.

- Thompson, E. J. (1954). The Rise and Fall of Maya Civilization. Norman: University of Oklahoma. 